\title{
Collapse and Reinforcement of Pipe-Framed Greenhouse under Static Wind Loading
}

\author{
Yasushi Uematsu $^{1}$ and Kazuya Takahashi ${ }^{2}$ \\ 1. National Institute of Technology (KOSEN), Akita College, Akita 011-8511, Japan \\ 2. Engineering Headquarters, Shimizu Corporation, Chuo-ku, Tokyo 104-8370, Japan
}

\begin{abstract}
The present paper investigates the collapse process of a pipe-framed greenhouse under static wind loading based on a non-linear finite element analysis. The purpose is to establish a more reasonable wind resistant design method for such structures. The structures are so flexible that the fluid-structure interaction (FSI) is considered in the analysis. In practice, iterative analyses of the structure's response and the wind pressure distribution on the deformed structure are made. The wind direction is normal to the ridge. Computational fluid dynamics (CFD) analysis with a RANS turbulence model is used for evaluating the time-averaged wind pressure coefficient distribution on the structure. Both the geometric and the material non-linearity are considered in the structural analysis. The collapse behavior obtained is consistent with the practical one often observed in damage investigations. Based on the results, discussion is made of the validity of the current design guideline commonly used in Japan. The same analysis is carried out for various reinforced models. The effect of each reinforcement method on the improvement of wind resistance of the structure is investigated on the basis of the allowable stress and deformation limits specified in the current design guideline.
\end{abstract}

Key words: Pipe-framed greenhouse, static wind loading, collapse process, reinforcement, FSI, CFD, finite element method (FEM).

\section{Introduction}

Pipe-framed greenhouses, widely used in the agricultural and horticultural industries in Japan, are generally designed to a lower level of structural safety than conventional structures, because of the need to minimize capital costs, the demand for a higher level of light transmission and so on. Being inherently light and flexible, they are vulnerable to wind loading and often damaged by strong winds. Fig. 1 shows an example of collapsed pipe-framed greenhouses. This type of collapse or the depression of arch pipes is commonly observed in damage investigations. Collapse of the structure by strong winds may cause severe damage to crops inside the greenhouse, resulting in a significant economic loss. Therefore, the wind resistance of the structure is one of the greatest concerns for structural engineers when designing greenhouses.

Wind loads and wind resistant design of

Corresponding author: Yasushi Uematsu, president, research fields: wind and structural engineering. greenhouses have been studied by many researchers. Regarding the wind loads, many field measurements were conducted to investigate the characteristics of wind pressures on full-scale greenhouses or similar structures (e.g., Hoxey and Wells [1], Wells and Hoxey [2], Hoxey and Richardson [3, 4], Richardson [5]). Richardson and Westgate [6] measured the wind pressure distribution on a pipe-framed greenhouse and the strains induced in the two frames, pin-jointed and rigidly held at the base, which were placed adjacent to the center of the greenhouse. A comparison was made for the strains between the direct measurement and the prediction from a two-dimensional finite element analysis using the measured wind pressure coefficient distribution. The results indicated that the wind loads could be regarded as quasi-static. This feature implies that the distribution of time-averaged wind pressures on the structure plays an important role in the structural analysis and design.

Such field studies have been regarded as practical approaches providing the most reliable data. However, 


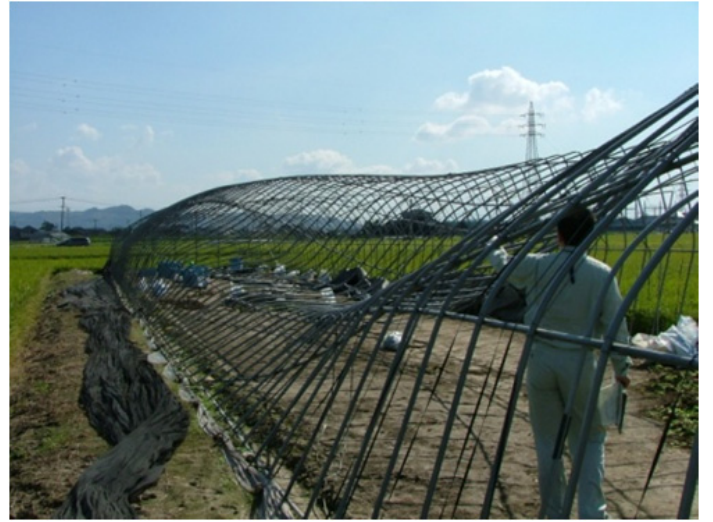

Fig. 1 Collapsed pipe-framed greenhouse due to typhoon.

they have a difficulty in acquiring data due to unstable and unpredictable weather conditions. Therefore, many wind tunnel studies have been conducted to investigate the characteristics of wind pressures on greenhouses in turbulent boundary layers (e.g., Toy and Tahouri [7], Tahouri et al. [8]). Yang et al. [9] measured the mean wind pressure distributions on single-span plastic greenhouses and solar greenhouses, which are popular in China. They derived critical wind speeds causing damage to these greenhouses. Recently, Kwon et al. [10] investigated the wind pressure distributions on single-span greenhouses with four different cross-sections using a large-scale wind tunnel. Moriyama et al. [11-13] carried out extensive researches of wind pressure distributions on pipe-framed greenhouses. All of these wind tunnel studies focused on the mean (time-averaged) wind pressure coefficients. On the contrary, Uematsu et al. $[14,15]$ discussed the wind pressure coefficients for designing the main wind force resisting systems of pipe-framed greenhouses, focusing on the dynamic load effects of approaching turbulent flow.

Many researchers have applied computational fluid dynamics (CFD) analyses to the evaluation of wind pressure coefficients on various greenhouses (e.g., Mathew and Meyer [16, 17], Reichrath and Davies [18], Mistriotis and Briassoulis [19]). Most of them used standard $k-\varepsilon$ turbulence model and/or renormalization group (RNG) $k-\varepsilon$ turbulence models. Recently, Kim et al. [20] evaluated the wind pressures on two types of single-span greenhouses in a wind tunnel. The experimental results were compared with those of CFD analyses using various turbulence models in order to select the most appropriate model. Accordingly, they selected the Shear Stress Transport (SST) $k$ - $\omega$ model. Then, Kim et al. [21] evaluated the wind pressure coefficients for various types of greenhouses using the developed CFD model. Note that all of these numerical studies focused on the time-averaged wind pressure coefficients.

Regarding the wind pressure distributions on buildings with cylindrical roofs, which are similar in shape to pipe-framed greenhouses, experimental and/or numerical studies have been made by many researchers (e.g., Castelli et al. [22], Qiu et al. [23]). Recently, Natalini and Natalini [24] made a review of previous studies of wind loads on enclosed buildings with vaulted roofs. Most of those studies also focused on the time-averaged wind pressure coefficients.

The structural systems and members of greenhouses are quite different from those of ordinary buildings. Kendirli [25] investigated a method of structural analysis for greenhouses commonly used in Turkey. Iribarne et al. [26] developed a computer model for designing multi-span greenhouses using an object-oriented technique. Ha et al. [27] developed a method for updating finite element model of multi-span greenhouse based on ambient vibration measurements. Hur and Kwon [28] carried out a fatigue analysis of greenhouse structure under wind load and self-weight, in which the fluctuating wind forces on the structure were evaluated based on the quasi-steady assumption. All of these analyses were carried out in the elastic range. Few studies have been made of the collapse of structures. Briassoulis et al. [29] analyzed the collapse of a multi-span greenhouse with vaulted roofs, which occurred during a day of heavy snow and moderate wind. Moriyama et al. [30, 31] discussed the causes of typhoon-induced damage to several greenhouses based on a linear structural analysis, in which they assumed that the wind pressure 
coefficient distribution on the structure did not change with the deformation of the structure. Ren et al. [32] developed a numerical model of three-dimensional frame of a large-span plastic greenhouse. Then, they made linear and non-linear stability analyses using this model. In the non-linear analysis they considered both the geometric and the material non-linearity. The wind loads were evaluated based on the relevant provisions of building standards. Few studies have been conducted on the collapse process of pipe-framed greenhouses. This is probably due to difficulties existing in the analysis. Both the geometric and the material non-linearity should be considered, because the deformation becomes rather large. Furthermore, the deformation alters the flow around the greenhouse significantly, resulting in a great change in the wind pressure coefficient distribution on the structure. Therefore, the effect of fluid-structure interaction (FSI) should be considered in the analysis.

In Japan, pipe-framed greenhouses are usually designed based on an allowable stress or deformation limit following the structural guideline of Japan Greenhouse Horticulture Association. In the allowable deformation design, it is assumed that the structure will not lose the resistance against wind loading due to the restraint effect of surrounding members, even if the stresses induced in some members exceed the elastic range. However, such an assumption has not been verified yet. Furthermore, it is not clear how much safety margin the structure has, when a pipe-framed greenhouse is designed based on such criteria. Therefore, the present paper investigates the collapse process of a pipe-framed greenhouse under static wind loading based on a three-dimensional non-linear finite element analysis, in which both the geometric and the material non-linearity as well as the FSI effect are considered. In practice, CFD and structural analyses are carried out in terns.

The wind resistance of pipe-framed greenhouses can be improved by reinforcing the main frame, or adding reinforcing members to the main frame. Indeed, many kinds of reinforcements have been employed. In the second part of this paper, discussion is made of the effect of reinforcement on the strength of pipe-framed greenhouses under static wind loading based on the allowable stress and deformation limits as well as on the buckling. As mentioned above, the wind loads on pipe-framed greenhouses can be regarded as quasi-static. Therefore, this paper focuses only on the static wind loading. The behavior under dynamic wind loading is the subject of our future study.

\section{Analytical Model and Condition}

\subsection{Analytical Model}

The analytical model (basic model) of the present study is illustrated in Fig. 2a, which is one of the most typical pipe-framed greenhouses constructed in Japan. The dimensions are as follows: i.e., span $B=5,400$ mm; ridge height $H=3,000 \mathrm{~mm}$; eaves height $h=$ $1,550 \mathrm{~mm}$; distance between adjacent arch pipes $d=$ $450 \mathrm{~mm}$; and length $L=21,600 \mathrm{~mm}$. The arch pipes are carbon steel tubes for general structural purpose (JIS G3445 STKM11A) with Young's modulus $E=$ $2.05 \times 10^{5} \mathrm{~N} / \mathrm{mm}^{2}$, Poisson's ratio $v=0.33$ and yield stress $\sigma_{y}=175 \mathrm{~N} / \mathrm{mm}^{2}$. The outer diameter $\phi$ and thickness $t$ of arch pipes are $22.2 \mathrm{~mm}$ and $1.2 \mathrm{~mm}$, respectively. The structure consists of 49 arch pipes, 3 horizontal tie beams connecting the arch pipes together at the location of knees and ridge, and 22 gable columns. The horizontal tie beams are connected to the arch-pipes by means of "cross bands". Entrance doors in the gable walls are not modeled, which will not affect the general behavior of the structure significantly. The load bearing width of arch pipe and gable column is $450 \mathrm{~mm}$ except for the gable frames; the value for the edge frame is $450 / 2 \mathrm{~mm}$.

Fig. $2 \mathrm{~b}$ shows the reinforcements made on the basic frame, which are investigated in the present study. "Case 0 " represents the basic frame without reinforcement. The reinforcing members are also circular pipes of outer diameter $\phi=22.2 \mathrm{~mm}$ and thickness $t=1.2 \mathrm{~mm}$. They are pin-jointed to the basic frame or the ground. 


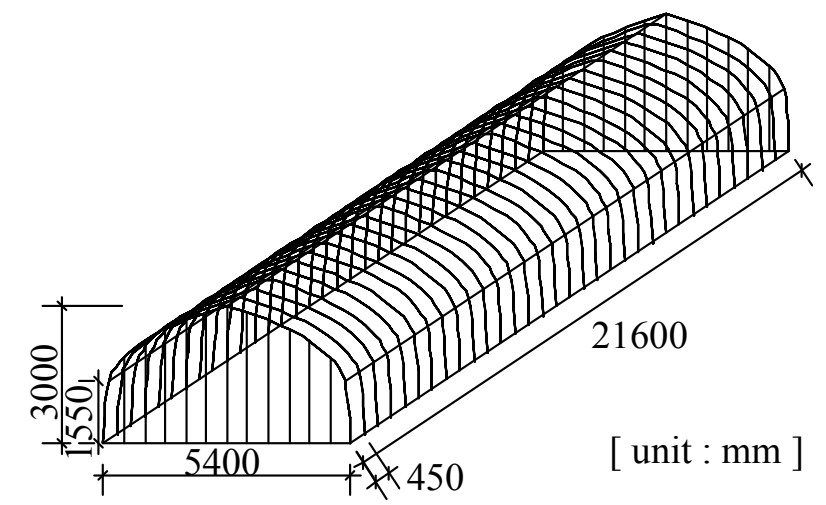

(a) Dimensions

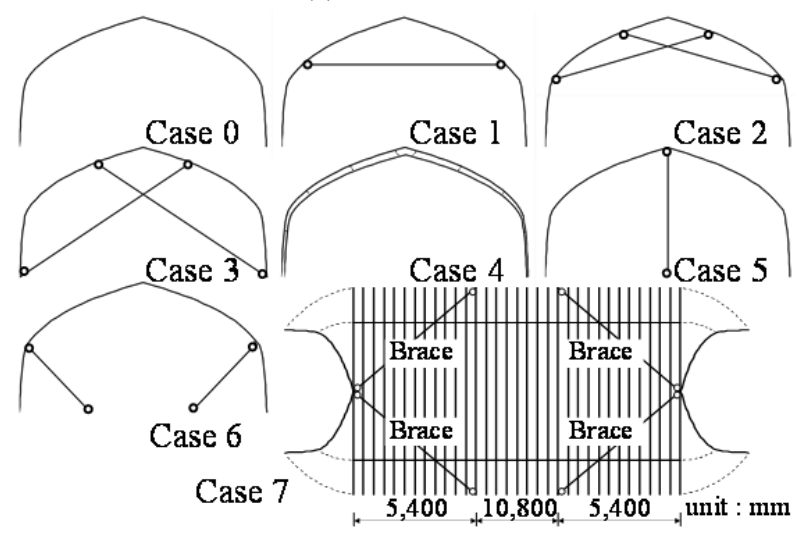

(b) Reinforcement

Fig. 2 Analytical model and reinforcement of pipe-framed greenhouse.

In Cases 1 to 6 the reinforcing members are attached to the basic frame at an interval of $1.8 \mathrm{~m}$ in the ridge direction. Four diagonal arches (braces) are attached to the gable walls in Case 7 . Note that the figure of Case 7 shows a development view of the structure. Such reinforcements as Cases 3, 5 and 6 are regarded as temporary. The reinforcing members, which may interrupt the work inside the greenhouse, will be attached to the basic frame when strong winds are expected to blow.

\subsection{Finite Element Structural Analysis}

The non-linear finite element analysis of the pipe-framed greenhouse under static wind loading is made by using commercial computer software "ABAQUS 6.13". In the analysis, both the geometric and the material non-linearity are taken into account. The arc-length method is employed, in which the arc

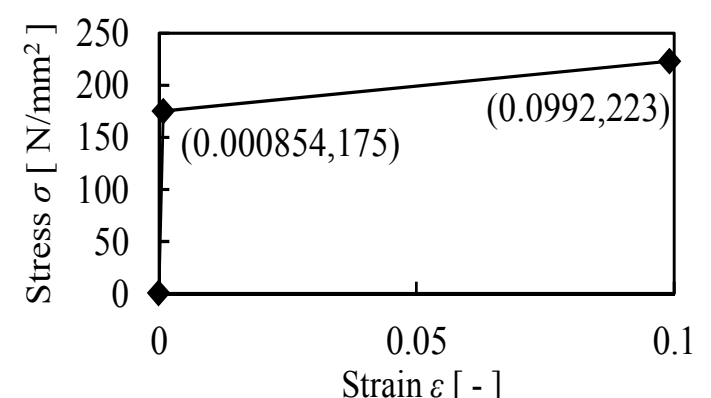

Fig. 3 Stress-strain relationship for the structural members.

length is controlled so that the equilibrium path up to the collapse of the structure can be obtained. The stress-strain $(\sigma-\varepsilon)$ relationship of the material is represented by a bi-linear model (see Fig. 3), in which the secondary gradient is assumed $E / 420$ according to Ogawa et al. [33]. The arch pipes and gable columns are clamped to the ground. The multipoint constraint is applied to the boundary condition of the structural members; that is, at the joint of arch pipe and horizontal tie beam, the displacements of the two members are the same, but the members can rotate independently with each other. Arch pipe is divided into 58 beam elements. The other members are divided into beam elements of $150 \mathrm{~mm}$ length. The size of these elements was determined based on the computation accuracy and load. In addition to the element nodes constituting the structural frame, reference nodes for creating three dimensional shape data used for the CFD analysis are arranged. They neither constitute any structural elements nor affect the structural analysis. Both nodes are shown in Fig. 4.

\subsection{CFDAnalysis}

The CFD analysis of wind pressure distribution on the structure is made by using an open source code "OpenFOAM" (ver. 2.3.1). Note that the present simulation corresponds to a wind tunnel experiment with a 1:40 scale model (see Ref. [14]). The wind direction is parallel to the gable walls, or normal to the ridge. The airflow is assumed isothermal and incompressible. Fig. 5 shows the computational domain normalized by $B$ (span of the structure, which is used as a reference 


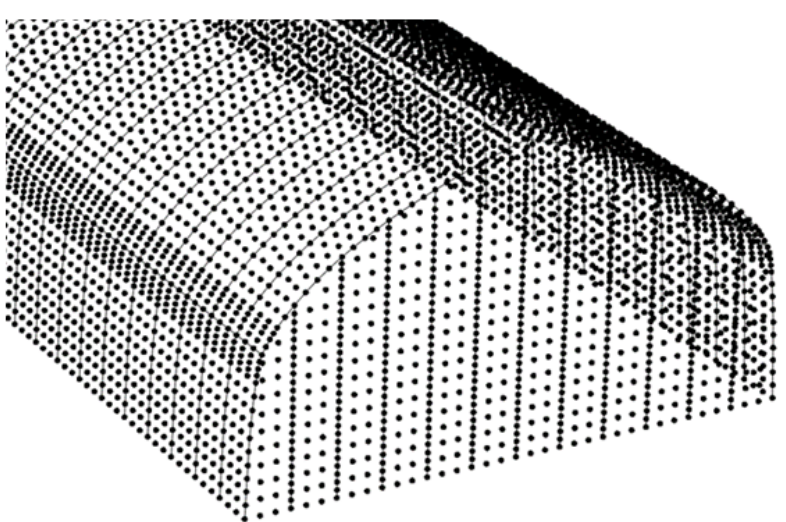

Fig. 4 Element nodes and reference nodes for finite element analysis.

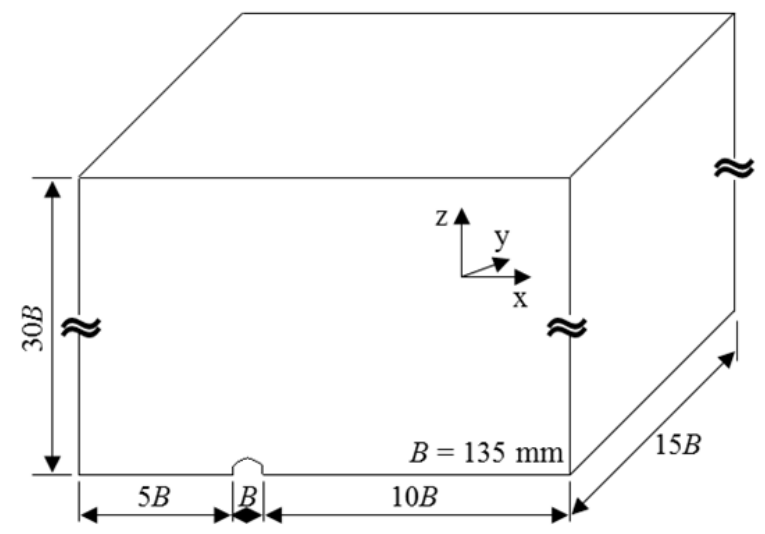

(a) Computational domain

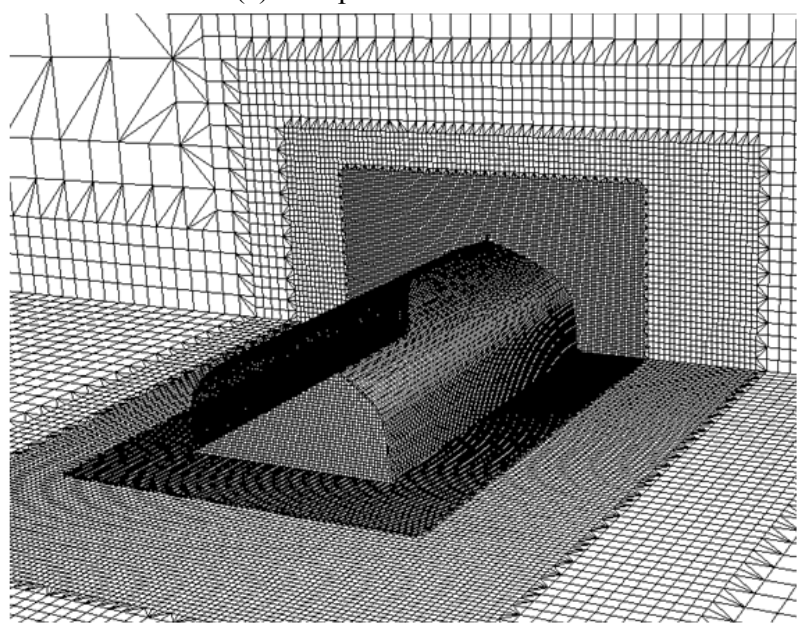

(b) Mesh division near the model

Fig. 5 Computational model for the CFD analysis.

length) and the mesh division near the model. The domain is subdivided into seven levels of meshes in order to reduce the computation load. The maximum mesh size is approximately $250 \mathrm{~mm}$ near the upper boundary, while the minimum is approximately $2 \mathrm{~mm}$ near the model. Considering the symmetry of the structure, the analysis is carried out for the half space divided by the central plane (see Fig. 5b). The distribution of mean wind pressures on the structure is calculated by using a Reynolds Averaged Navier-Stokes (RANS) turbulence model. The analytical conditions, summarized in Table 1, are determined based on the reproducibility of the previous wind tunnel experiment [14] and the convergence of computation.

Fig. 6 shows the vertical profiles of mean wind velocity, normalized by the value $U_{\text {ref }}$ at a reference height $Z_{\text {ref }}=700 \mathrm{~mm}$, and turbulence intensity at the location of the model's center with no model. The mean velocity profile is in good agreement with that given by the power law with an exponent of $\alpha=0.15$ (solid line), which corresponds to open-country exposure. It was found that the profiles agreed well with those of the wind tunnel flow [14], which are not shown in the figure.

Shown in Fig. 7 is a comparison between CFD analysis and wind tunnel experiment [14] for the distributions of mean external wind pressure coefficients $C_{p}$ at various cross-sections, in which $C_{p}$ is defined in terms of the mean velocity pressure $q_{H}$ at the ridge height $H$ and $\mu$ represents the distance of the cross-section from the central plane; i.e., $\mu / L=0$ corresponds to the central plane and $\mu / L=0.5$ to the gable wall. Note that each subfigure shows the $C_{p}$ distribution along the frame; the abscissa represents the distance $s$ along the frame from the windward column base, normalized by the maximum value $s_{\max }$. The agreement between these two results is fairly

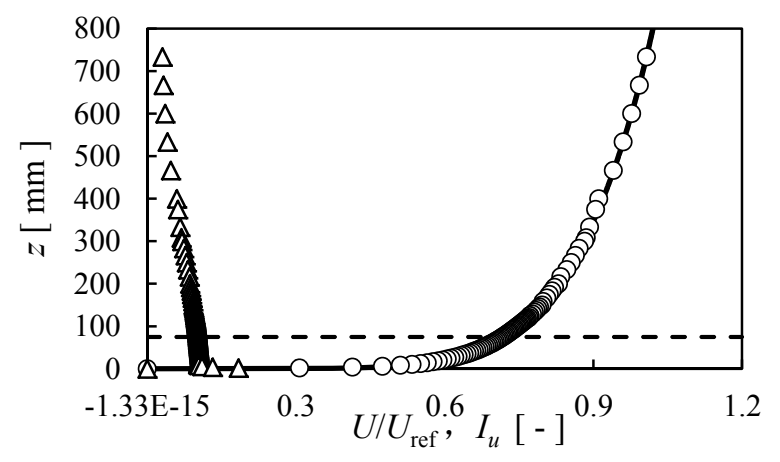

Fig. 6 Vertical profile of simulated approach flow. 
Table 1 Analysis conditions for CFD.

\begin{tabular}{ll}
\hline Inflow boundary & $U, k, \mathcal{E}$ : approximation, $p$ : gradient 0 \\
Floor boundary & Wall function \\
Model surface boundary & Wall function \\
Ceiling boundary & Slip condition \\
Side boundary & Wall function \\
Symmetry plane boundary & Symmetry plane \\
Outflow boundary & $U, k, \varepsilon$ : gradient $0 p$ : 0 \\
Turbulence model & Realizable $k$ - $\varepsilon$ model \\
Gradient scheme & Second-order finite difference scheme(Gauss linear) \\
Convection scheme & Van Leer splitting function(Gauss linear vanLeer) \\
Diffusion scheme & Second-order finite difference scheme(Gauss linear) \\
& $P:$ Generalized geometric-algebraic multi-grid (GAMG) \\
Linear solver & $U:$ preconditioned bi-conjugate gradient (PBiCG) \\
& $k, \varepsilon$ : solver that uses a smoother (smooth Solver) \\
Solution algorithm & SIMPLE method \\
\hline
\end{tabular}

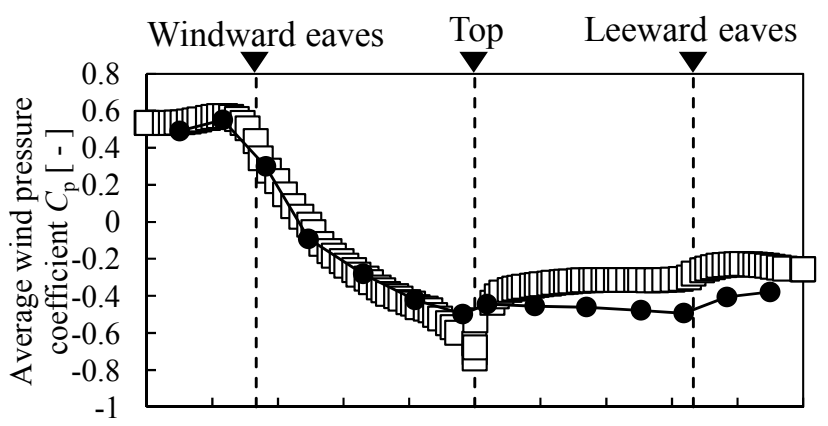

(a) $\mu / L=0$

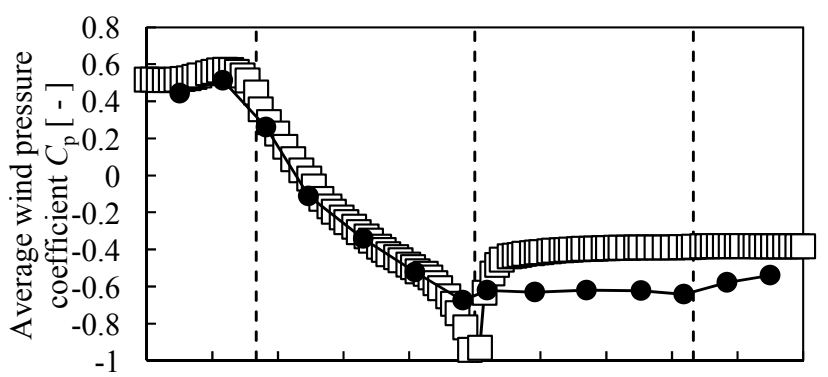

(c) $\mu / L=0.28$

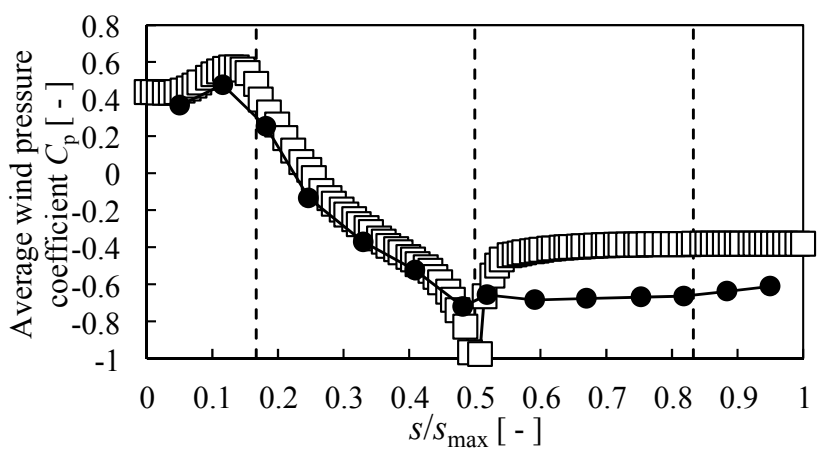

(e) $\mu / L=0.42$

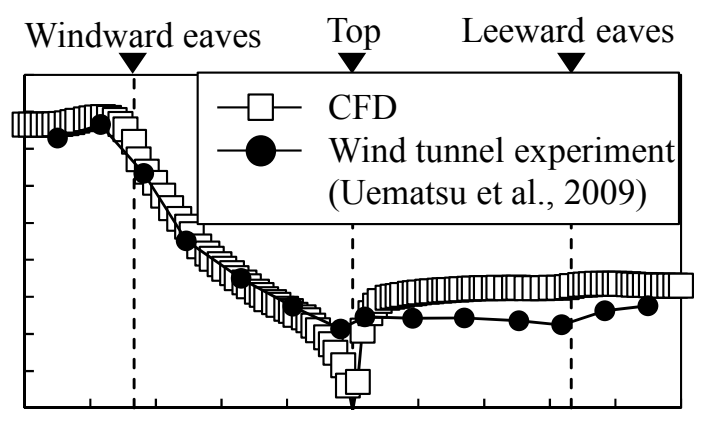

(b) $\mu / L=0.14$

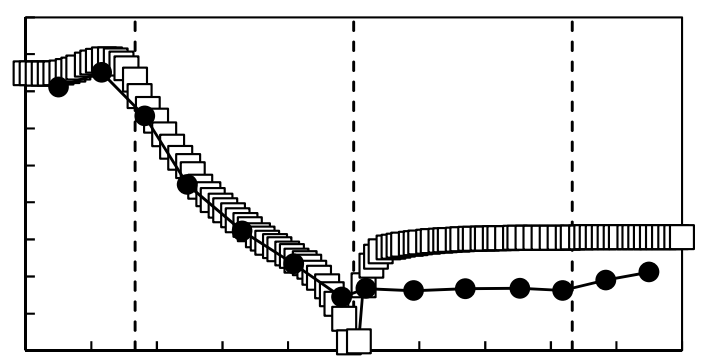

(d) $\mu / L=0.35$

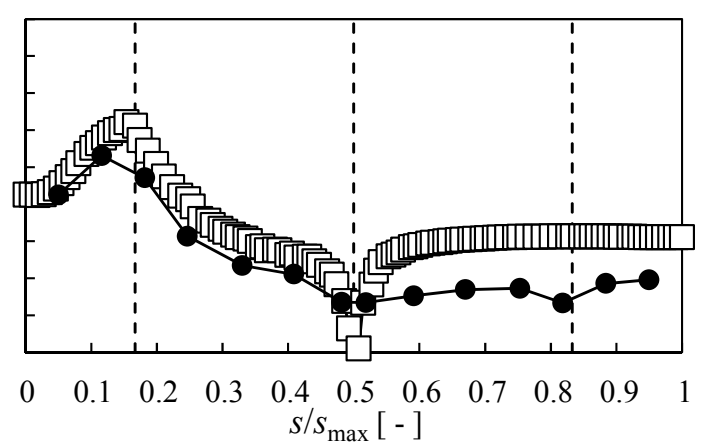

(f) $\mu / L=0.49$

Fig. 7 Comparison between CFD analysis and experiment for the distributions of mean wind pressure coefficients. 
good on the windward wall and roof, while somewhat poor on the leeward wall and roof, particularly for larger $\mu / L$ values. However, the influence of such a difference in the $C_{p}$ distribution on the collapse of the structure seems small, because the wind pressures on the windward area may play an important role on the deformation of the structure. Therefore, the following computations are made under the above-mentioned analytical condition.

\subsection{Method of FSI Analysis}

In this section, we analyze the behavior of pipe-framed greenhouse up to the collapse when the greenhouse is subjected to the static wind loading. Because the deformation of the structure becomes rather large, the wind pressure distribution on the structure may change significantly with the deformation. In order to consider such an FSI effect, CFD analysis and FEM (structural) analysis are statically coupled (see Fig. 8). Considering the collapse mode, as shown in Fig. 1, which is often observed in damage investigations, the wind direction is assumed to be normal to the ridge. Furthermore, the internal wind pressure is assumed to be zero; this assumption may not affect the deformation of the structure significantly. In this case, the net wind force provided by the difference between the external and internal wind pressures coincides with the external wind pressure.

First, the $C_{p}$ distribution on the un-deformed structure is obtained by CFD analysis (see Fig. 7). Then, the wind velocity $U_{H}$ is set to a small value $\Delta U_{H}$ and the wind force distribution on the structure is calculated by using the velocity pressure $q_{H}\left(=0.5 \rho U_{H}^{2}\right.$, with $\rho$ being the air density), the $C_{p}$ distribution and the load bearing width $d$. Next, the deformation of the structure subjected to this wind force is calculated by the finite element method (FEM). After that the wind velocity $U_{H}$ is increased by $\Delta U_{H}$ and the same procedure is repeated until a part of the structure other than the column bases touches the ground. In the case of

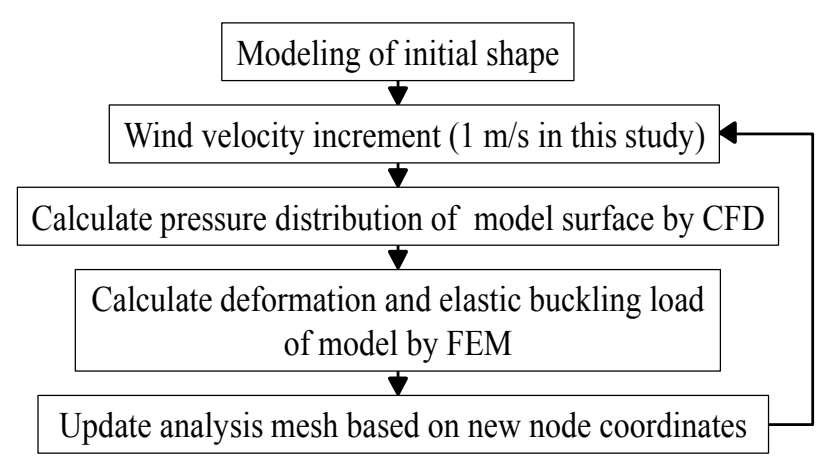

Fig. 8 Procedure of analysis with consideration of the FSI effect.

reinforced model, the analysis is repeated until the deformation of the frame reaches the allowable limit defined in the current design guideline; i.e., the horizontal displacement at the windward eaves of the central arch pipe is equal to $h / 35$. Linear buckling analysis is also performed based on an eigenvalue analysis. The value of $\Delta U_{H}$ is set to $1 \mathrm{~m} / \mathrm{s}$ in practice.

\section{Results and Discussion}

\subsection{Load-Displacement Relationship}

The load-displacement relationship for the basic model (Case 0) is shown in Fig. 9. Note that Fig. 9b is an enlarged view of the curve in a velocity pressure range up to $400 \mathrm{~N} / \mathrm{m}^{2}$. The vertical dashed and dotted lines represent the allowable stress and deformation limits specified in the current design guideline in Japan. The ordinate of the graph represents the velocity pressure $q_{H}$, and the abscissa the horizontal displacement of the central arch pipe at the windward eaves, which is used as an index for representing the deformation of the structure. The displacement linearly increases with an increase in $q_{H}$ up to the allowable stress limit, beyond which the curve shows a non-linearity. However, the non-linearity is not so significant up to the allowable deformation limit. The structure does not lose resistance against wind loading until a part of the arch pipe touches the ground. The maximum wind load (ultimate strength) cannot be obtained. This is probably because the collapse mode cannot be uniquely determined due to the redistribution 


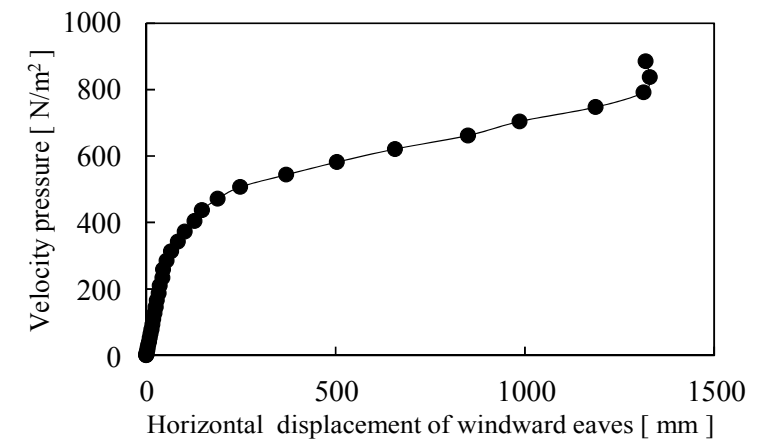

(a) Overall view

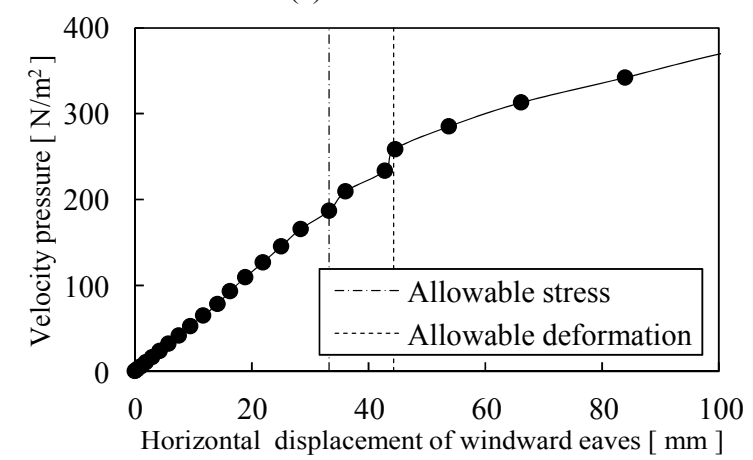

(b) Enlarged view

Fig. 9 Load-displacement curve for the central arch pipe.

of wind loads. Therefore, we cannot determine the design wind load based on the ultimate strength of the structure. It may be more reasonable to determine it based on a deformation limit. In this sense, the current design guideline based on the allowable deformation limit seems appropriate.

Fig. 10 shows the variation of the $C_{p}$ distribution and the deformation of the structure as the wind velocity $U_{H}$ is increased. The $C_{p}$ distribution is represented by a development view for the half area, considering the symmetry of the structure. Focusing on the $C_{p}$ distribution, we can find that the positive wind pressure area expands with the deformation of the structure. The area at $U_{H}=38 \mathrm{~m} / \mathrm{s}$ is much wider than that for the un-deformed structure, which is more than twice. As a result, the wind force acts on the structure so as to push the windward part of the structure down to the ground. The ultimate state looks similar to the collapse mode of practical pipe-framed greenhouses often observed in damage investigations (see Fig. 1). We carried out a similar response analysis, assuming that the $C_{p}$ distribution did not change with the deformation. The results, not shown here to save space, indicated that the structure deformed so as to inflate upward. Such a deformation is quite different from the practical collapse mode. Therefore, in order to reproduce the collapse process of the structure appropriately, it is necessary to consider the variation of the $C_{p}$ distribution with the deformation of the structure, or the FSI effect.

\subsection{Three Dimensional Effects}

Two-dimensional (2D) analysis for the arch pipe was also carried out in order to investigate the three-dimensional (3D) effect, or the effects of the horizontal tie beams connecting arch pipes together and the gable walls on the deformation of the whole structure. Fig. 11 shows a comparison between 2D

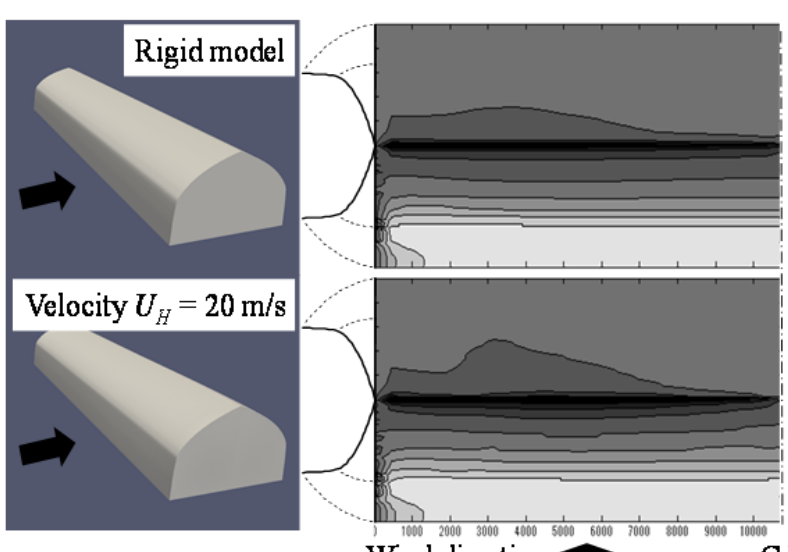

Wind direction-

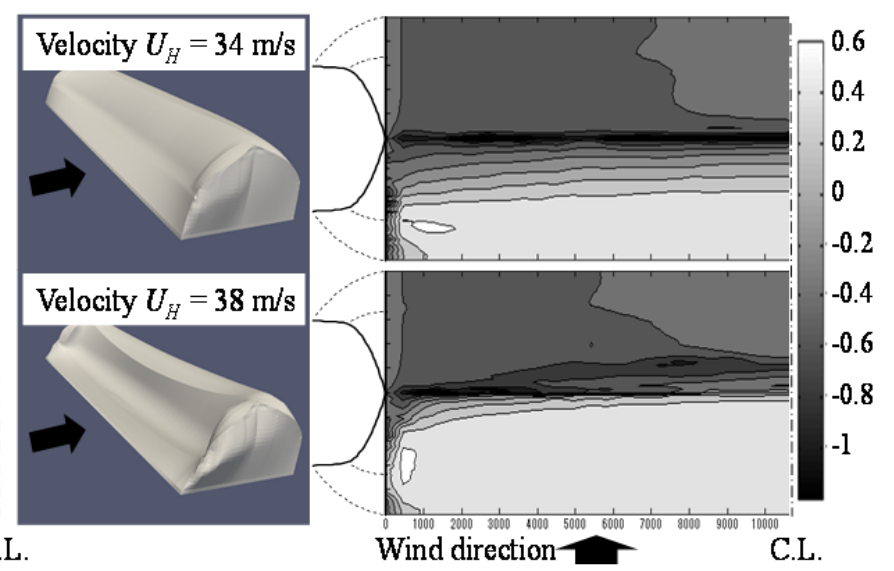

Fig. 10 Wind pressure coefficient distributions on the deformed structure. 


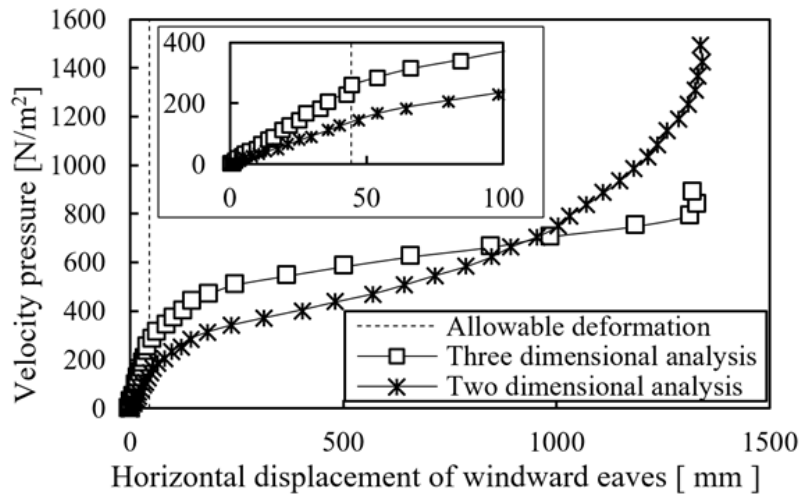

Fig. 11 Comparison between $2 D$ and 3D analyses for the load-displacement curve.

and 3D analyses for the load-displacement relationship of the central arch pipe. The upper left figure is an enlarged view of the curve in a velocity pressure range up to $400 \mathrm{~N} / \mathrm{m}^{2}$. The vertical dashed line represents the allowable deformation limit. It is clear that the results of the $2 \mathrm{D}$ and $3 \mathrm{D}$ analyses are different from each other significantly. When the horizontal displacement at the windward eaves is smaller than approximately $900 \mathrm{~mm}$, the 3D analysis provides smaller displacements than the $2 \mathrm{D}$ analysis. This is due to the restraint effect of horizontal tie beams and gable walls (3D effect). Comparing the velocity pressures providing the allowable deformation limit, the value obtained from the $3 \mathrm{D}$ analysis is approximately 1.8 times larger than that obtained from the 2D analysis. In other words, the 2D analysis requires larger rigidity of the structure when the structure is designed based on the allowable deformation limit. On the other hand, when the displacement exceeds about $900 \mathrm{~mm}$, the 3D analysis provides larger displacements than the $2 \mathrm{D}$ analysis.

Fig. 12 shows the $C_{p}$ distributions on the windward area of the central arch pipe, which are obtained from the $2 \mathrm{D}$ and $3 \mathrm{D}$ analyses, when the horizontal displacement at the windward eaves is $500 \mathrm{~mm}$. It is found that the slope of the curve obtained from the 2D analysis is steeper than that obtained from the $3 \mathrm{D}$ analysis. Although the displacements are the same (i.e., $500 \mathrm{~mm}$ ) in both analyses, the area of positive wind pressures and the magnitude of wind pressure coefficients are both larger in the 3D analysis than in the $2 \mathrm{D}$ analysis. Therefore, it can be said that larger deformation and earlier collapse may occur in the 3D analysis than in the $2 \mathrm{D}$ analysis.

\subsection{Reinforcement Effects}

Fig. 13 shows the load-displacement curves for the central arch pipe of the reinforced models (Cases 1-7, see Fig. 2).The vertical dashed line represents the allowable deformation limit. It is found that the wind loads providing the allowable deformation limit is increased by the reinforcement, except for Case 7, in which the diagonal arches do not affect the deformation of the central arch pipe. The load-displacement curves for all reinforced models exhibit similar behavior. The relation is almost linear up to the allowable deformation limit. At the allowable deformation limit, a plastic hinge is generated at the windward column base of the central arch pipe. However, the arch pipe is restrained by the other members, resulting in nearly elastic behavior of the structure as a whole. Therefore, the wind resistant design based on the allowable deformation limit specified in the current design guideline seems appropriate even in the reinforced structure cases.

Next, in order to investigate the reinforcement effects quantitatively, Table 2 summarizes the wind velocities providing the allowable stress limit $\left(U_{\mathrm{as}}\right)$, allowable deformation limit $\left(U_{\mathrm{ad}}\right)$ and linear buckling $\left(U_{\mathrm{B}}\right)$ for all cases. Note that the wind velocity shown in the table is a value at a height of $10 \mathrm{~m}$ above the ground. The symbol "-" indicates that the corresponding wind velocity is larger than $60 \mathrm{~m} / \mathrm{s}$. It is found that the diagonal braces used in Case 7 minutely affect the wind velocities providing the allowable stress and deformation limits. On the other hand, the in-frame reinforcements used in Cases 1 to 6 increase the values of $U_{\text {as }}$ and $U_{\text {ad }}$ significantly. However, linear buckling may occur at a wind velocity lower than $U_{\text {as }}$ and $U_{\text {ad }}$ in Case 1, where the tie bar is subjected to compression. In Case 5, the anchors of the reinforcing 
Table 2 Comparison between reinforced models for the wind velocities providing the allowable stress limit, the allowable deformation limit and the linear buckling.

\begin{tabular}{llll}
\hline Case & $\begin{array}{l}\text { Allowable stress } \\
U_{\mathrm{as}}(\mathrm{m} / \mathrm{s})\end{array}$ & $\begin{array}{l}\text { Allowable } \\
\text { deformation } \\
U_{\mathrm{ad}}(\mathrm{m} / \mathrm{s})\end{array}$ & $\begin{array}{l}\text { Linear buckling } \\
U_{\mathrm{B}}(\mathrm{m} / \mathrm{s})\end{array}$ \\
\hline 0 & 19.7 & 23.8 & - \\
1 & 22.3 & 29.0 & 20.3 \\
2 & 23.5 & 29.5 & - \\
3 & 23.8 & 30.6 & - \\
4 & 21.6 & 26.9 & - \\
5 & 23.6 & 29.3 & 48.2 \\
6 & 23.8 & - & 31.1 \\
7 & 20.7 & 23.6 & - \\
\hline
\end{tabular}

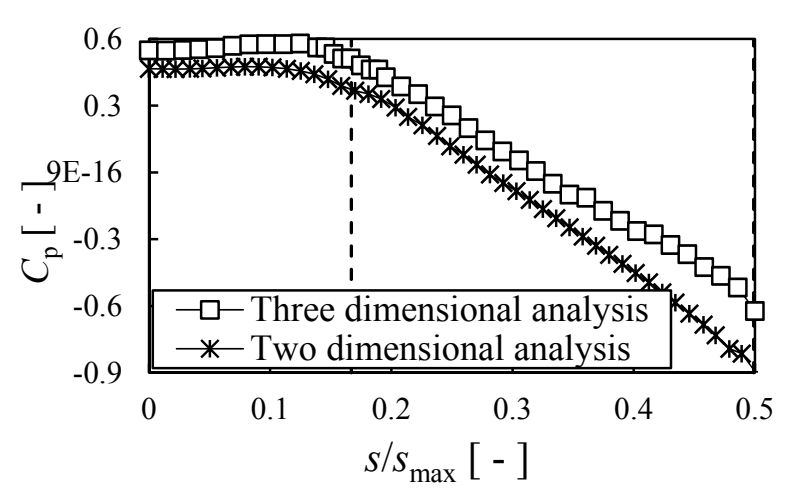

Fig. 12 External wind pressure coefficient distributions on the deformed structures when the horizontal displacement at the windward eaves is $500 \mathbf{~ m m}$.

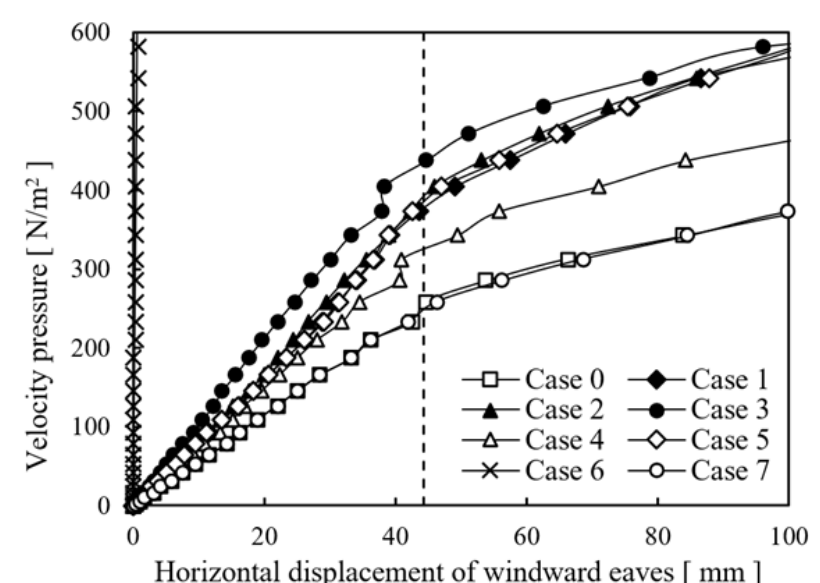

Fig. 13 Load-displacement curve for the central arch pipe of the reinforced model.

members (vertical supporting members) should be strong enough to resist large pull-out forces, because the members are first subjected to tension. Buckling may occur when the axial forces induced in these members change from tension to compression due to the deformation of arch pipes as the wind velocity increases. Case 6 seems very effective for improving the wind resistance of the structure. The deformation of the windward eaves can be restrained by the windward diagonal reinforcing members, resulting in a larger $U_{\text {ad }}$ value. However, buckling may occur in these members.

\section{Concluding Remarks}

Three-dimensional structural analysis was carried out in order to investigate the behavior of a pipe-framed greenhouse, commonly used in Japan, under static wind loading. The wind pressures on the deformed structure were estimated from a CFD analysis with a RANS turbulence model. In the structural analysis, both the geometric and the material non-linearity were taken into account. The static fluid-structure interaction (FSI) was also considered. The simulated collapse mode corresponded well to that observed in damage investigations. Without considering the FSI effect, the result was found to be quite different from the practical one. Therefore, it is necessary to consider the FSI effect to understand the non-linear behavior of the structure appropriately.

Because the wind pressure distribution changes with the deformation of the structure, the structure does not show the maximum strength (ultimate strength) until a part of the frame other than the column bases touches the ground. Therefore, we cannot define the design wind load based on the maximum load. It may be more reasonable to define it based on the allowable deformation limit in the same manner as in the current design guideline commonly used in Japan.

The effects of reinforcements on the wind resistance of pipe-framed greenhouses were also investigated based on the allowable stress and deformation limits as well as on the linear buckling. The results indicate that the reinforcement improves the wind resistance of the structure significantly. However, the effect depends on the type of reinforcement. 


\section{Acknowledgments}

This work was financially supported by the Steel Structure Research and Education Promotion Project of the Japan Iron and Steel Federation in FY2016.

\section{References}

[1] Hoxey, R. P., and Wells, D. A. 1977. "Full-Scale Wind Pressure Measurements on a Twin-Span $12.2 \mathrm{~m} \times 12.2 \mathrm{~m}$ Inflated Roof Greenhouse." Journal of Wind Engineering and Industrial Aerodynamics 2: 211-21.

[2] Wells, D. A., and Hoxey, R. P. 1980. "Measurements of Wind Loads on Full-Scale Greenhouses." Journal of Wind Engineering and Industrial Aerodynamics 6: 139-67.

[3] Hoxey, R. P., and Richardson, G. M. 1983. "Wind Loads on Film Plastic Greenhouses." Journal of Wind Engineering and Industrial Aerodynamics 11: 225-37.

[4] Hoxey, R. P., and Richardson G. M. 1984. "Measurements of Wind Loads on Full-Scale Film Plastic Clad Greenhouses." Journal of Wind Engineering and Industrial Aerodynamics 16: 57-83.

[5] Richardson, G. M. 1993. "Full-Scale Wind Load Measurements on a Single-Span Film Plastic-Clad Livestock Building.” Journal of Agricultural Engineering Research 55: 251-64.

[6] Richardson, G. M., and Westigate, G. R. 1986. "Full-Scale Measurements of the Wind Loads on Film Plastic Clad Greenhouses: A Comparison of Measured and Calculated Strains on the Supporting Hoops of a Tunnel Greenhouse." Journal of Agricultural Engineering Research 33: 101-10.

[7] Toy, N., and Tahouri, B. 1988. "Pressure Distributions on Semi-cylindrical Structures of Different Geometrical Cross-Sections." Journal of Wind Engineering and Industrial Aerodynamics 29: 263-72.

[8] Tahouri, B, Toy, N., and Savory, E. 1990. "Surface Pressures and Wake Flows Associated with Highly Curved Agricultural Buildings." Journal of Wind Engineering and Industrial Aerodynamics 36: 319-27.

[9] Yang, Z. Q., Li, Y. X., Xue, X. P., Huang, C. R., and Zhang, B. 2013. "Wind Loads on Single-Span Plastic Greenhouses and Solar Greenhouses." American Society for Horticultural Science 23 (5): 622-8.

[10] Kwon, K., Kim, D., Kim, R., Ha, T., and Lee, I. 2016. "Evaluation of Wind Pressure Coefficients of Single-Span Greenhouses Built on Reclaimed Coastal Land Using a Large-Sized Wind Tunnel.” Biosystems Engineering 141: 58-81.

[11] Moriyama, H., Sase, S., Uematsu, Y., and Yamaguchi, T.
2008. "Pressure Coefficient of a Pipe-Framed Greenhouse and Influence of the Side Gable Openings Using a Wind Tunnel." The Journal of the Society of Agricultural Structures Japan 38 (4): 1-12.

[12] Moriyama, H., Sase, S., Uematsu, Y., and Yamaguchi, T. 2010. "Wind Tunnel Study of the Interaction of Two or Three Side-by-Side Pipe-Framed Greenhouses on Wind Pressure Coefficients." Transaction of the ASABE (American Society of Agricultural and Biological Engineers) 53 (2): 585-92.

[13] Moriyama, H., Sase, S., Uematsu, Y., Ishii, M., and Okushima, L. 2015. "Influence of Ridge Height of Pipe-Framed Greenhouses on Wind Pressure Coefficients." Transaction of the ASABE (American Society of Agricultural and Biological Engineers) 58 (3): 763-9.

[14] Uematsu, Y., Tanaka, S., Moriyama, H., and Sase, S. 2009. "External Wind Pressure Coefficients for Designing the Main Wind Force Resisting Systems of Pipe-Framed Greenhouse." The Journal of the Society of Agricultural Structures, Japan 40 (3): 29-38. (in Japanese)

[15] Uematsu, Y., Nakahara, K., Tanaka, S., Moriyama, H., and Sase, S. 2009. "Effects of Sidewall Openings on the Wind Loads on Pipe-Framed Greenhouses." In Proceedings of the Seventh Asia-Pacific Conference on Wind Engineering.

[16] Mathews, E. H., and Meyer, J. P. 1987. "Numerical Modelling of Wind Loading on a Film Clad Greenhouse.' Building and Environment 22 (2): 129-34.

[17] Mathews, E. H., and Meyer, J. P. 1988. "Computation of Wind Loads on a Semicircular Greenhouse." Journal of Wind Engineering and Industrial Aerodynamics 29: 225-33.

[18] Reichrath, S., and Davies T. W. 2002. "Computational Fluid Dynamics Simulations and Validation of the Pressure Distribution on the Roof of a Commercial Multi-span Venlo-Type Glasshouse." Journal of Wind Engineering and Industrial Aerodynamics 90: 139-49.

[19] Mistriotis, A., and Briassoulis, D. 2002. "Numerical Estimation of the Internal and External Aerodynamic Coefficients of a Tunnel Greenhouse Structure with Openings." Computers and Electronics in Agriculture 34: 191-205.

[20] Kim, R., Lee, I., and Kwon, K. 2017. "Evaluation of Wind Pressure Acting on Multi-span Greenhouses Using CFD Technique, Part 1: Development of the CFD Model." Biosystems Engineering 164: 235-56.

[21] Kim, R., Hong, S., Lee, I., and Kwon, K. 2017. "Evaluation of Wind Pressure Acting on Multi-span Greenhouses Using CFD Technique, Part 2: Application of the CFD Model." Biosystems Engineering 164: 
257-80.

[22] Castelli, M. R., Toniato, S., and Benini, E. 2011. "Numerical Analysis of Wind Loads on a Hemicylindrical Roof Building." International Journal of Mechanical, Aerospace, Industrial, Mechatronic and Manufacturing Engineering 5 (8): 1669-76.

[23] Qiu, Y., Sun, Y., Wu. Y., and Tamura, Y. 2014. "Modeling the Mean Wind Loads on Cylindrical Roofs with Consideration of the Reynolds Number Effect in Uniform Flow with Low Turbulence." Journal of Wind Engineering and Industrial Aerodynamics 129: 11-21.

[24] Natalini, B., and Natalini, M. B. 2017. "Wind Loads on Buildings with Vaulted Roofs and Side Walls-A Review." Journal of Wind Engineering and Industrial Aerodynamics 161: 9-16.

[25] Kendirli, B. 2006. "Structural Analysis of Greenhouses: A Case Study in Turkey." Building and Environment 41: 864-71.

[26] Iribarne, L., Torres, J. A., and Pena, A. 2007. "Using Computer Modeling Techniques to Design Tunnel Greenhouse Structures." Computers in Industry 58: 403-15.

[27] Ha, T., Kim, J., Cho, B. H., Kim, D. J., Jung, J. E., Shin, S. H., and Kim, H. 2017. "Finite Element Model Updating of Multi-span Greenhouses Based on Ambient Vibration Measurements." Biosystems Engineering 161:
145-56.

[28] Hur, D. J., and Kwon, S. 2017. "Fatigue Analysis of Greenhouse Structure under Wind Load and Self-weight." Applied Science 7 (12): 1274.

[29] Briassoulis, D., Dougka, G., and Dimakogianni, D. 2016. "Analysis of the Collapse of a Greenhouse with Vaulted Roof." Biosystems Engineering 151: 495-509.

[30] Moriyama, H., Sase, S., Kowata, H., and Ishii, M. 2003. "Engineering Analysis of the Greenhouse Structures Damaged by Typhoon 0221 in Chiba and Ibaraki." The Journal of the Society of Agricultural Structures Japan 34 (3): 199-212. (in Japanese)

[31] Moriyama, H., Sase, S., Okushima, L., and Ishii, M. 2015. "Review: Which Design Constraints Apply to a Pipe-Framed Greenhouse?." Japan Agricultural Research Quarterly 49 (1): 1-9.

[32] Ren, J., Wang, J., Guo, S., Li, X., Zheng, K., and Zhao, Z. 2019. "Finite Element Analysis of the Static Properties and Stability of a Large-Span Plastic Greenhouse." Computers and Electronics in Agriculture 165: 104957.

[33] Ogawa, H., Tsuge, I., Sato, Y., Hoshiba, S., and Yamashita, S. 1989. "Experimental Analysis on Strength of Pipe-Houses with Ground Anchoring (1) - Actual Size Experiment." Journal of the Society of Agricultural Structures Japan 19 (3): 29-38. (in Japanese) 